\title{
An engineering model for the prediction of the sound radiation from a railway track
}

\author{
Xianying Zhang*, David Thompson, Erika Quaranta, Giacomo Squicciarini \\ Institute of Sound and Vibration Research, University of Southampton, Southampton SO17 \\ 1BJ, UK \\ *Corresponding author: xianyingzhang96@gmail.com
}

\begin{abstract}
Models for predicting railway rolling noise such as TWINS are well-established and have been validated against field measurements. However, there are still some areas where improvements are required. In particular, the radiation from the rail is based on a model of a rail in free space whereas in reality the rail is located close to the ground; there are also limitations in the existing model for the sound radiation from the sleepers. Besides, the influence of the ballast absorption on the sound power radiated by the track is neglected. This paper draws on recent research into the effects of the proximity of the rail and sleeper to an absorptive ground on their sound radiation, based on the boundary element method. In reality, the rail is located above the ballast over part of its length, and attached periodically to the concrete sleepers elsewhere. The sound radiation of the rail for those two situations can be predicted using the $2 \mathrm{D}$ boundary element method. In order to obtain a realistic rail radiation model for engineering applications, a method to combine those two results is proposed and the resulting average rail radiation is verified by using a 3D boundary element model. An improved sleeper radiation model is also proposed and verified using the 3D boundary element model. These new engineering models for the rail and sleeper radiation have been used together with TWINS to predict the sound radiation from operational tracks and the results have been compared with field measurements. Compared with the TWINS model, the rail radiation is found to be increased below $300 \mathrm{~Hz}$, but decreased above $1 \mathrm{kHz}$; the sound radiation from the sleeper is reduced compared with the TWINS model below $600 \mathrm{~Hz}$.
\end{abstract}

Keywords: sound radiation from railway track; absorptive ground; railway ballast; boundary element method; radiation ratio; elementary noise sources. 


\section{Introduction}

The most important source of railway noise in most situations is rolling noise, which is caused by wheel and rail vibration induced by their combined surface roughness at the wheel/rail interface. Both the wheels and the track contribute significantly to the rolling noise; their relative importance depends on details of the design, the roughness spectra and the train speed $[1,2]$.

Remington presented analytical formulae for the prediction of wheel/rail rolling noise in urban rail transit systems [3]. These were obtained based on the characterization of the wheel/rail dynamic system in [4] and the roughness spectra on the contact surfaces of wheels and rails. The model was verified by comparing the predictions with field measurements both from a full-scale transit system and a small-scale engineering test vehicle.

Remington [5] later presented a comprehensive analytical model to predict wayside noise generated by wheel/rail rolling noise based on the models presented in the earlier study [3, 4]. In order to improve the analytical model, some modifications were made: inclusion of ground effects in the sound propagation model; and prediction of the average wayside noise during a train pass-by rather than the noise at a particular train position during the pass-by. The ground was modelled as a finite impedance plane using the approach of Chessell [6]. Comparison with field measurements showed, however, that the predicted results 'without ground' agreed much better with the measured data than the results including the ground effect. It was suggested that this may be because of the omission of absorptive ballast in the model.

Later, Thompson extended these engineering methods for predicting rolling noise [7], using finite element models for the wheel vibration modes and coupling the wheel and rail in both lateral and vertical directions at the contact point. Improved radiation models were also included. A software package, known as TWINS ('Track-Wheel Interaction Noise Software'), was produced and extensive validation experiments carried out [7, 8]. TWINS is currently the most widely used railway rolling noise prediction model. Results can be obtained either in terms of sound power or the average sound pressure during the passage of a train at specified positions at the trackside. Despite its widespread use, however, the model still has some limitations.

One of the simplifying assumptions in the sound radiation models was that the sound power radiated from the rails was calculated for a situation in which they radiate into free space, whereas in reality they are located in close proximity to the ground. This ground consists of 
ballast, which is partially absorptive, and sleepers (or cross ties) which are acoustically reflective. It has been shown by the authors, by using the boundary element method (BEM), that the ground close to the rail has an important effect on the sound power radiated by the rail [9]. These results were also validated against laboratory measurements on a 1:5 scale rail. This ground influence was also analysed by Ryue et al. using a wavenumber domain numerical method [10].

There are also limitations in the way that the sleeper radiation is treated in TWINS. The sleepers are assumed to be embedded in a rigid ground and the effect of multiple sleepers is taken into account in a heuristic way [11]. In [12], improved boundary element models for the sound radiation from sleepers have been presented and validated through laboratory measurements on a scale model in the presence of an absorptive ground consisting of a layer of melamine foam.

The ballast is also an important component of the track. Railway ballast is a porous medium with absorptive properties [13-15]. This can modify the sound radiation of the rail and the sleeper. It has been shown from simulations and scale model experiments that the absorption of the ballast is beneficial in reducing the radiated sound from the rail for both vertical and lateral motion above $900 \mathrm{~Hz}$ [15]. Measurements of the absorption of railway ballast obtained in a reverberant chamber were presented by Broadbent et al. [14]; the results were fitted to a multiple layer model with flow resistivities between 25 and $51 \mathrm{kPa} . \mathrm{s} / \mathrm{m}^{2}$. However, in [13] the flow resistivity of railway ballast was measured as $200 \mathrm{~Pa} . \mathrm{s} / \mathrm{m}^{2}$. In [15] the flow resistivity and porosity was measured on samples of 1:5 scale ballast with the correct gradation. The mean flow resistivity was found to be $280 \pm 20 \mathrm{~Pa} . \mathrm{s} / \mathrm{m}^{2}$ and the porosity was determined as 0.46 . Although the ballast absorption should strictly be modelled as an extended reaction medium [15], the Delany and Bazley model [16] for an infinite layer with a flow resistivity of $50 \mathrm{kPa} . \mathrm{s} / \mathrm{m}^{2}$ has been found to give reasonable predictions for the propagation at grazing incidence above a layer of ballast [17].

It should be noted that the Delany and Bazley model is unphysical, as discussed by Dragna and Blanc-Benon [18], which is a particular problem if used in time-domain simulations. They recommend physically-admissible models such as that by Hamet and Bérengier [19] and the four-parameter Attenborough model [20]. Compared with the result in [17], Attenborough et al. [21] obtained significantly better fits to measured data for the propagation above a layer of ballast with the 'slit-pore' model. Nevertheless, in the context of the current study, the relevant 
effect of the ballast is its influence on the source radiation when the rail or sleeper is in close proximity to the ground. For this, the authors have previously found [9] that physically admissible models such as the Johnson-Allard model [22, 23], based on measured parameter values for the flow resistivity, do not give such good agreement with measurements as the Delany and Bazley model with a flow resistivity of $50 \mathrm{kPa} . \mathrm{s} / \mathrm{m}^{2}$. This is likely to be caused by the effects of sound propagation through the medium, which cannot be included in a boundary element approach and is therefore beyond the scope of the current study.

The aim of this paper is to propose an updated engineering model for the sound radiation from a railway track by combining and extending the improved models for the rail and sleeper radiation presented in $[9,12]$. The main novelty is to propose a method to combine 2D BEM results for different conditions to approximate the $3 \mathrm{D}$ behaviour. Compared with the existing models in TWINS, these improved models are more realistic and rigorous. The updated models include the effect on the sound power radiated from the rail of the proximity of the ground (absorptive ballast or reflective concrete sleepers) as well as the effect of the periodic support. An improved sleeper radiation model is also presented that takes into account the multiple sleepers, connected via the rails, as well as the acoustic boundary conditions of the absorptive ballast. An important motivation for the work is to be able to make a more accurate distinction between the cases of a slab track and a ballasted track, which have different ground absorption and therefore could not be distinguished in the existing radiation models.

In Section 2 the ballast impedance is included in the 2D BEM model for the sound radiation from the rail and the 3D BEM model for the sleeper. In reality, only part of the rail is located above the ballast, whereas the remainder is attached periodically to the concrete sleepers. These two situations are predicted separately using the 2D BEM in Section 2. However, a method is required to combine them appropriately. To establish such a method, calculations are presented from a 3D BEM model of a finite length of track in Section 3. From these results, an approximate method to predict the average rail radiation is proposed in Section 4. Then, the updated models for the rail and sleeper radiation are combined together with the TWINS model to give predictions of the sound radiation from the complete track. Results are shown in Section 5 for operational tracks and are compared with existing field measurements. 


\section{The effects of the ballast absorption on the track sound radiation}

In this section the ballast absorption is included in the BEM radiation models for the rail from [9] and sleeper from [12]. In each case, the sound radiation is presented in terms of the radiation ratio, or radiation efficiency, which can be expressed as

$$
\sigma=\frac{W}{\rho_{0} c_{0} S\left\langle\overline{\left.v^{2}\right\rangle}\right.}
$$

where $\rho_{0}$ and $c_{0}$ are the density of air and the speed of sound, respectively; $W$ is the radiated sound power; $S$ is the surface area of the vibrating structure and $\left\langle\overline{v^{2}}\right\rangle$ is the surface-averaged mean-square velocity normal to the surface in the frequency band of interest. The quantities $\sigma$, $W$ and $v$ are functions of frequency.

\subsection{Effects of the ground on rail radiation}

To represent the rail, the 2D boundary element mesh shown in Figure 1 is used. It has been shown in [24] that the structural wavelength of waves in the rail is much greater than the acoustic wavelength for most practical frequencies and therefore a $2 \mathrm{D}$ model for the rail is generally satisfactory. At very low frequencies, where the decay rate of vibration in the rail is high, a correction is required from the 2D result to allow for the 3D nature of the source.

A UIC60 profile is used for the rail in this model. The dashed line is a symmetry plane in the model introduced to represent a rigid ground beyond the region covered by the ballast. The ballast has a width of $2 \mathrm{~m}$ at the top and $3 \mathrm{~m}$ at the bottom, with a depth of $0.5 \mathrm{~m}$. As in [9] it is represented by the impedance of an infinite layer according to the Delany and Bazley model [16] with a flow resistivity of $50 \mathrm{kPa} . \mathrm{s} / \mathrm{m}^{2}$. The rail foot is located $50 \mathrm{~mm}$ above the ground surface. In addition, two models are considered in which the ground is rigid: one with the same separation of $50 \mathrm{~mm}$ below the rail foot and the other in which the rail foot is mounted directly on the rigid surface and assumed not to radiate (in reality a rubber rail pad is located between the rail foot and the sleeper).

The radiation ratio of the rail is predicted for both vertical and lateral motion of the rail; in each case a uniform motion is imposed on the surface of the rail. Results are shown in Figure 2 for these three ground conditions. A fourth case is shown for reference, in which the rail is located in free space. As pointed out in [9], this has a slope of $30 \mathrm{~dB} /$ decade at low frequencies, corresponding to a line dipole, see Figure 3(a). For vertical motion, Figure 2(a), compared with 
the result for a rail in free space, the radiation ratio is reduced at low frequency by the proximity to the ground, which changes the line dipole characteristic to a line quadrupole (slope of 50 $\mathrm{dB} /$ decade). This can be explained by the presence of image sources due to the ground reflection, see Figure 3(c). When the rail is located on the rigid ground the slope at low frequency changes to $10 \mathrm{~dB} /$ decade, indicative of a line monopole, see Figure 3(b). Around $800 \mathrm{~Hz}$ the result above the ground in Figure 2(a) rises to a peak. A sharp peak also occurs at $3.4 \mathrm{kHz}$; at this frequency the gap below the rail is equal to half the acoustic wavelength. When the ballast absorption is introduced, the radiation ratio at low frequency is increased compared with the result for a rigid ground, but above $400 \mathrm{~Hz}$ it is reduced. The difficulty is how to combine the results obtained in these different conditions; this is addressed in Section 4.

For lateral motion of the rail, the results have a similar trend in each case $(30 \mathrm{~dB} / \mathrm{decade}$ slope at low frequency) but the results at low frequency are increased by the presence of the ground. Compared with the result above a rigid ground, the inclusion of ballast absorption gives a reduction in the radiation ratio over much of the frequency range.

(a)
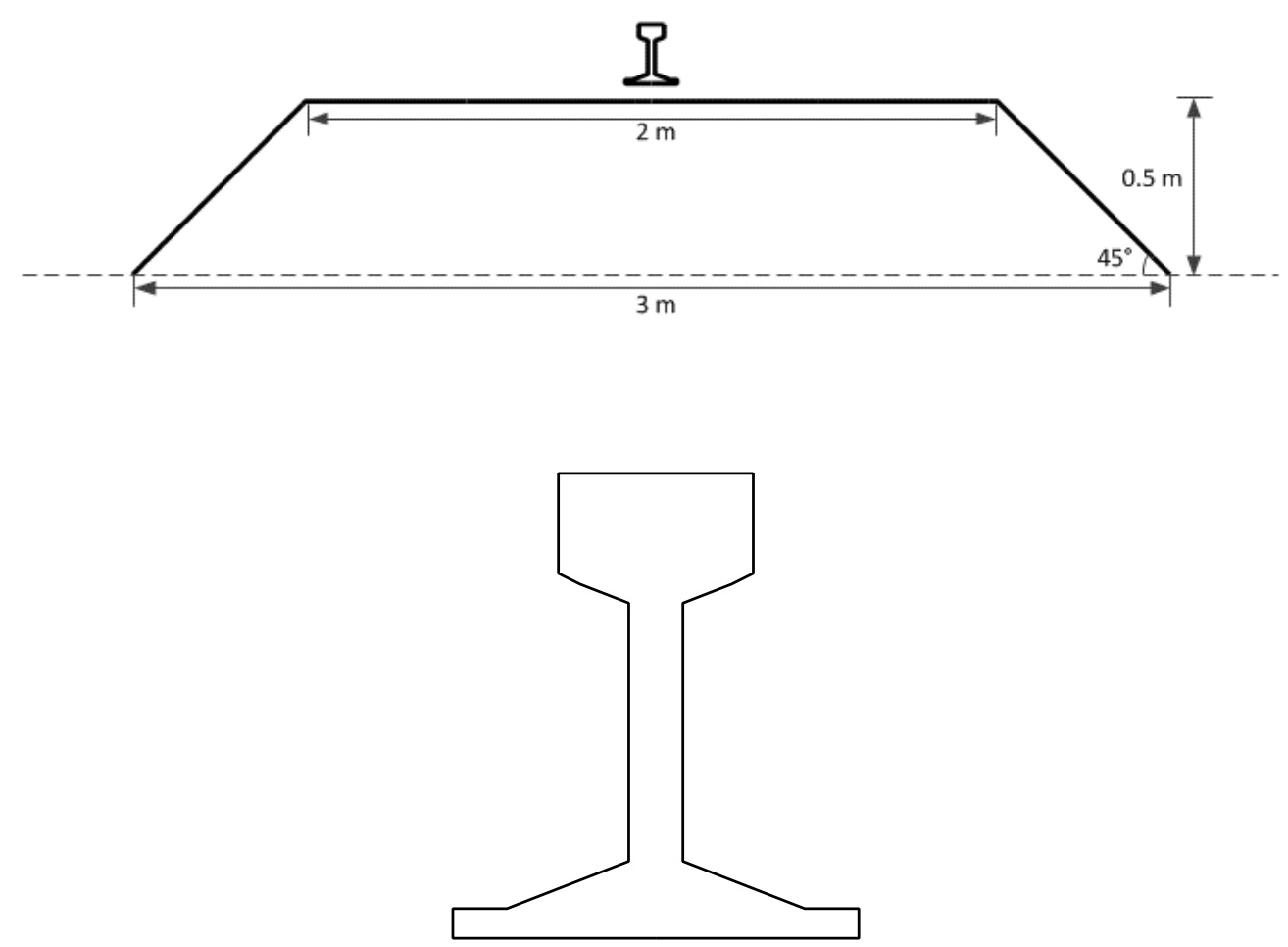

(b)

Figure 1 (a) Illustration of the boundary element model of the rail $50 \mathrm{~mm}$ above the ground (ballast) and (b) detail of the rail mesh 

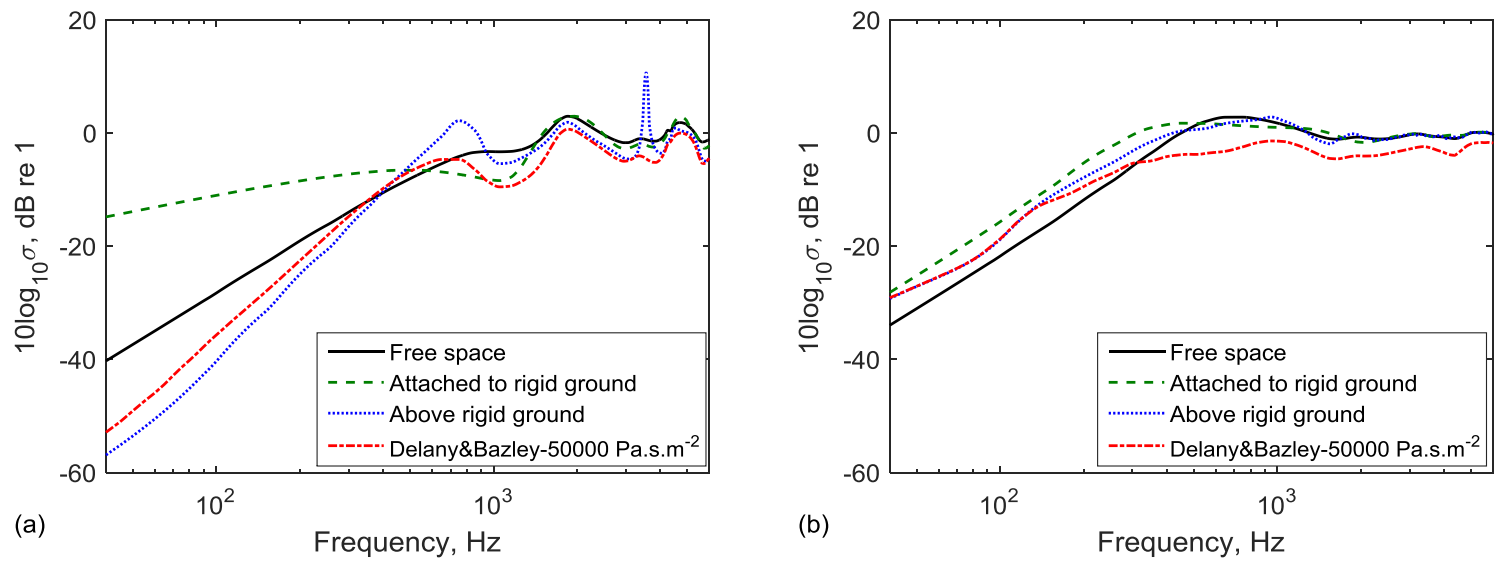

Figure 2 Effects of ground on the rail radiation. (a) Vertical motion; (b) Lateral motion.

(a)

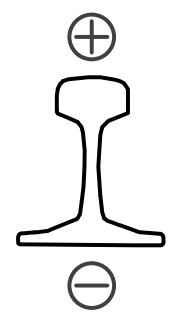

(b)

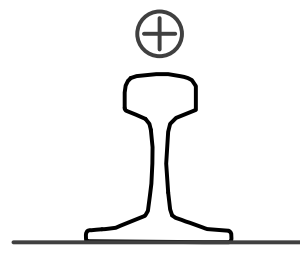

(c)

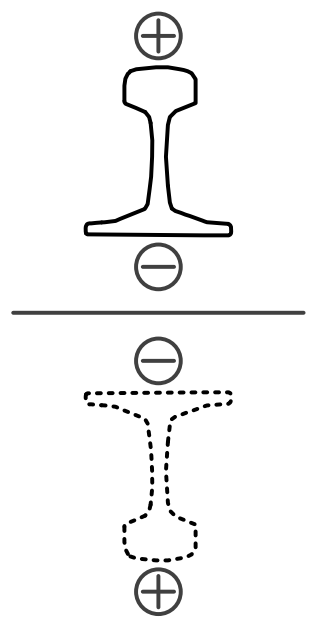

Figure 3 Indication of equivalent elementary sources representing the rail. (a) Rail in free space dipole; (b) rail on rigid ground-monopole; (c) rail above rigid ground - quadrupole.

\subsection{Effects of ballast on sleeper radiation}

For the sleepers, a three-dimensional boundary element model is used to assess the effect of the ballast absorption on their sound radiation. Although it was found in [15] that the ballast should be represented by an extended reaction model, in order to use the boundary element method the calculations here are limited to representing the ballast surface by an impedance. It has been found previously [12] that it is sufficient to consider only three adjacent sleepers in determining their radiation ratio. This is sufficient at low frequency because the response to a force on the rail decays rapidly along the rail so that the response of sleepers further from the excitation point is negligible. At higher frequencies, although the attenuation along the rail is smaller, each sleeper can be treated as an independent source because they are further apart 
than half the acoustic wavelength. Therefore, as before, only three sleepers are included in the model. These are assigned vibration amplitudes of $0.5,1$ and 0.5 to represent the relative vibration transmitted by the rail excited at a point above the central sleeper at low frequencies [12].

The sleepers are assumed to be fully embedded in the ballast so only their upper surface is visible. Three orthogonal symmetry planes are used in the model, as shown in Figure 4. The lower plane represents a rigid ground below the ballast as before; the other two planes are introduced to allow the model to be limited to one quarter of its size. The ballast bed has a width of $4 \mathrm{~m}$ at the top and $6 \mathrm{~m}$ at the bottom $(2 \mathrm{~m}$ and $3 \mathrm{~m}$ after allowing for the symmetry plane). It has a height of $500 \mathrm{~mm}$ as before. The length of the ballast region in the direction along the track is chosen according to the frequency range [12], as listed in Table 1; the mesh shown in Figure 4 is the high frequency model. The element size used in these models is also listed in Table 1. The sleepers, shown by the red outline in Figure 4, have a reduced length of $1.25 \mathrm{~m}(0.625 \mathrm{~m}$ after allowing for the symmetry plane) and a width of $0.2 \mathrm{~m}$. This reduced length (the full length of the sleepers is usually around $2.5 \mathrm{~m}$ ) is used to approximate the effect on the radiated power that occurs when the excitation from the rail is applied at $0.5 \mathrm{~m}$ from one end of the sleeper [12].

Figure 5 shows the radiation ratios obtained using this model. Three lines are compared. The result for three sleepers embedded in a rigid ground is greater than that for a single sleeper at low frequencies and then oscillates about the single sleeper result at higher frequencies. The third line shows the results when the three sleepers are embedded in a ground with the impedance derived from the Delany \& Bazley model of ballast. As can be seen, it will radiate up to $2 \mathrm{~dB}$ less noise than for a rigid ground between about $100 \mathrm{~Hz}$ and $1 \mathrm{kHz}$.

Table 1 Element size and the length of the track in the BE model in different frequency ranges

\begin{tabular}{|l|c|c|c|}
\hline Frequency range, $\mathrm{Hz}$ & $20 \sim 250$ & $200 \sim 1000$ & $800 \sim 2000$ \\
\hline Element size, $\mathrm{m}$ & 0.3 & 0.075 & 0.04 \\
\hline Length of the track bed, $\mathrm{m}$ & 15 & 4.25 & 2.0 \\
\hline
\end{tabular}




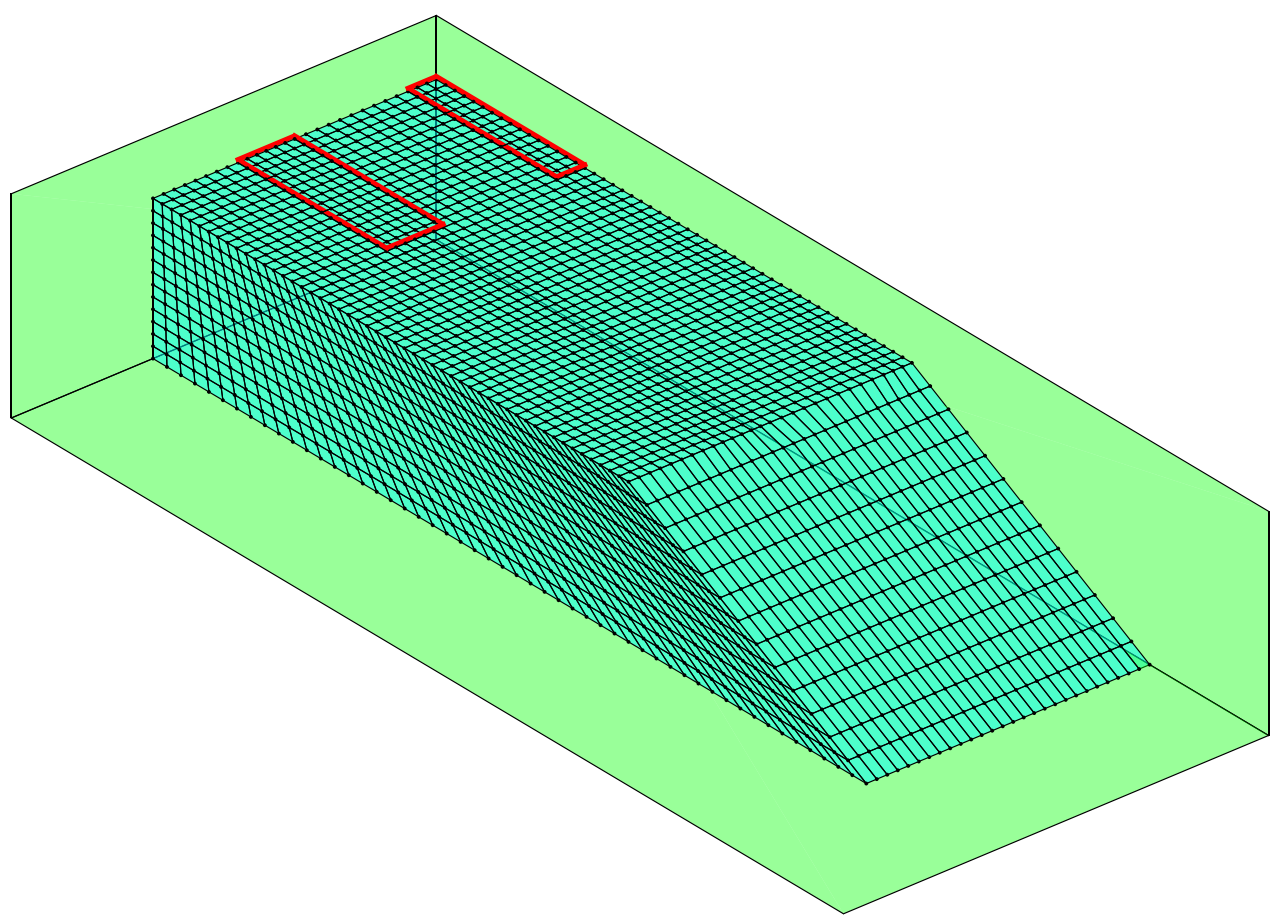

Figure 4 Mesh of one quarter of the domain for multiple sleepers embedded in ballast (high frequency model)

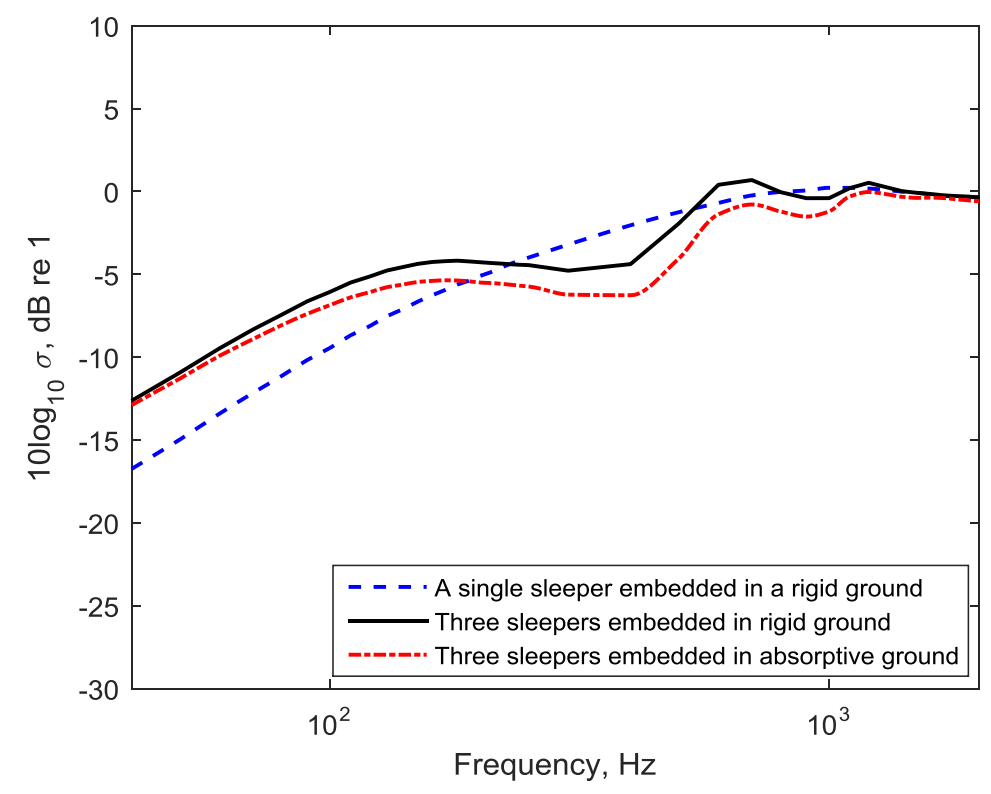

Figure 5 Effects of ballast absorption on the sleeper radiation

\section{Three-dimensional boundary element model of the track}

\subsection{Boundary element model}

In Section 2.1 various 2D BEM models for the rail were introduced. In reality the rail is supported periodically with regions above the ballast alternating with the regions attached to 
the sleepers. To see the effect of this periodic arrangement, a 3D boundary element model of the track is introduced here. The model is shown in Figure 6 and consists of a $3.6 \mathrm{~m}$ long section of track with two rails and six sleepers, at a spacing of $0.6 \mathrm{~m}$. The distance between the centres of the two rails is $1.5 \mathrm{~m}$ and the dimensions of the sleepers are $2.5 \mathrm{~m} \times 0.2 \mathrm{~m}$. The width of the top surface of the ballast bed is $3.5 \mathrm{~m}$, while its base is $4.5 \mathrm{~m}$ wide; it has a depth of $0.5 \mathrm{~m}$. The gap between the rail foot and the ballast surface is $0.05 \mathrm{~m}$. The ballast surface is represented by the same impedance model as in the previous section. A model in which the ballast surface is assumed to be rigid is also considered for comparison. A ground plane is included below the ballast region by using a half space formulation. Similarly, 'symmetry' boundary conditions are also employed at the two ends of the model, by adding additional terms to the Green's functions to allow for image sources. Each 'symmetry' plane only accounts for reflections from the actual model and not for the image sources in the other 'symmetry' region; consequently the effective length of the track model is $10.8 \mathrm{~m}$ (the actual BEM model plus the two symmetry regions). As this length is greater than the acoustic wavelength for frequencies above $30 \mathrm{~Hz}$ the model can be used to represent an infinitely long track above this frequency. A maximum element size of $0.03 \mathrm{~m}$ is used in the model, which has a total of 48000 elements. In order to avoid excessive calculation times, the results are obtained only up to $1 \mathrm{kHz}$.
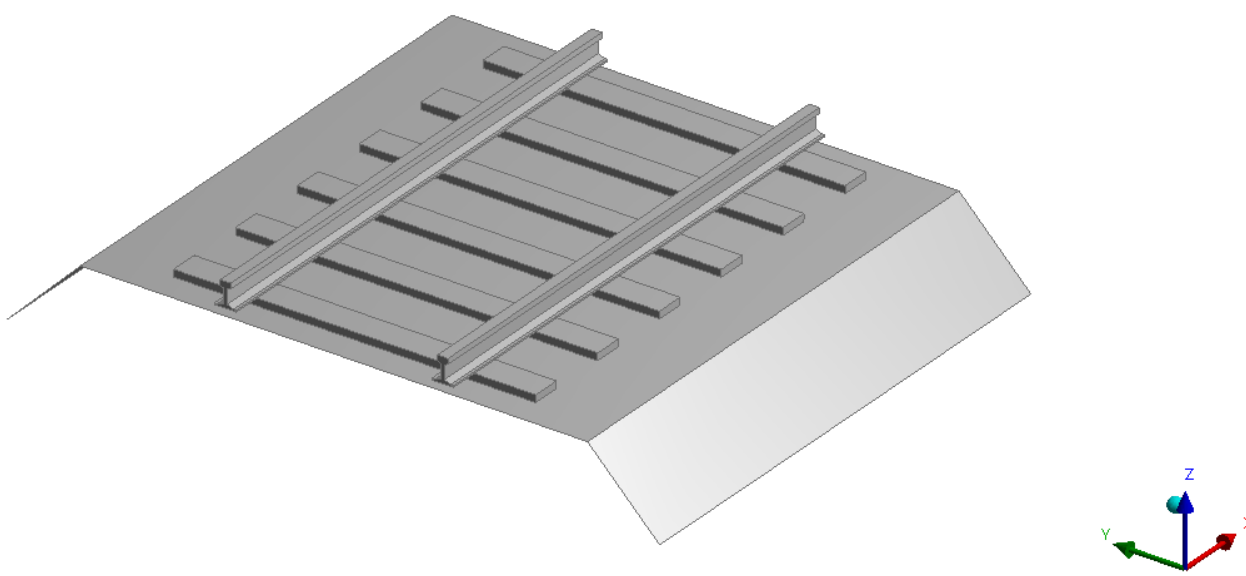

Figure 6 Three-dimensional boundary element model of the track

\subsection{Results for the rail with uniform vibration}

One rail in the track model is assumed to vibrate uniformly with a unit velocity amplitude over its whole length. Both vertical and lateral motions are considered separately. At this stage the sleepers (and ground) are assumed not to vibrate. The vibration of the sleepers is introduced in Section 3.4 below. 
Figure 7 presents the results in terms of the sound power per unit length of track. Results are given for cases in which the ballast surface is either rigid or assigned the ballast impedance. Additionally a result is shown for a rail in free space. For the vertical vibration, Figure 7(a), there are dips in the sound power curves at around $200 \mathrm{~Hz}$ for the absorptive ground and $300 \mathrm{~Hz}$ for the rigid ground. Below this frequency the slope of these curves is similar to the line monopole result (rail attached to rigid ground), whereas above this frequency it is similar to the line quadrupole result (rail above the ground), see Figure 2(a). The reason for the dips will be explored further in Section 4.1. Inclusion of the ballast absorption shifts the location of the dip; it also causes quite a large difference in the sound power between 500 and $1000 \mathrm{~Hz}$ where the peak is attenuated. These results are quite different from the result for the rail in free space.

For the lateral motion of the rail, Figure 7(b), the results follow the same trend at low frequency as a line dipole, as in Figure 2(b). The differences due to the ballast impedance are negligible below $200 \mathrm{~Hz}$, increasing to about $4 \mathrm{~dB}$ at higher frequency. The sound radiation of the rail close to the ground is greater than that of the rail in free space below $350 \mathrm{~Hz}$.
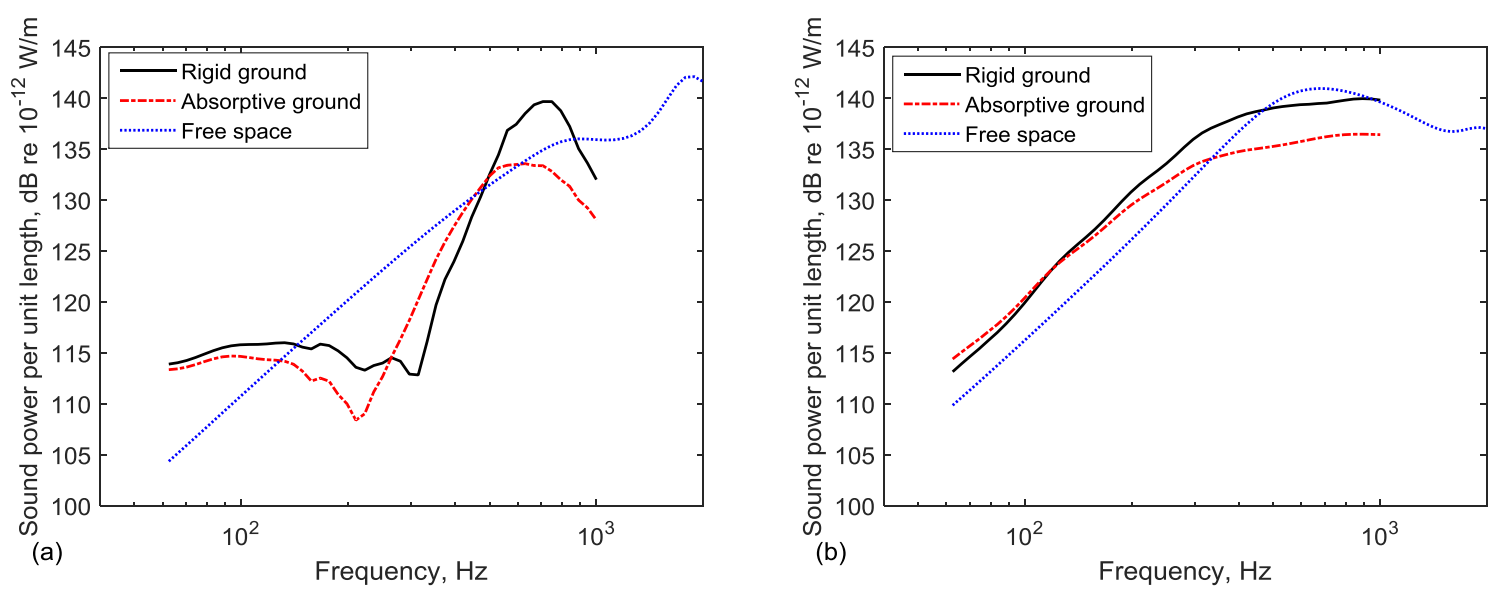

Figure 7 Comparison of the rail radiation from the 3D BE model for a rigid ground and an absorptive ground. (a) Vertical motion; (b) Lateral motion.

Qualitatively it appears that the results for the vertical rail vibration are a combination of the 2D results for the different regions (on the sleeper and above the ballast). To explore these effects further, some additional calculations are presented, focussing on the vertical motion of the rail for the case of a rigid ground. In Figure 8(a) results are shown for models in which there are 6,3 or 0 sleepers in the $3.6 \mathrm{~m}$ length of track. The case of 6 sleepers was shown already in Figure 7(a). When only three sleepers are included in the model, i.e. with a spacing of $1.2 \mathrm{~m}$, the sound power below $150 \mathrm{~Hz}$ is reduced by about $6 \mathrm{~dB}$ compared with the case of 6 sleepers, and the dip in the results moves to a lower frequency. When there are no sleepers 
in the model, this corresponds to the case of a rail above a rigid ground. Hence, this result has the acoustic properties of a line quadrupole and is similar to the result from the $2 \mathrm{D}$ model shown in Figure 2(a) [9]. The results in all three cases are similar above $500 \mathrm{~Hz}$.

In Figure 8(b) results for three different widths of sleeper are shown and compared with that for the rail attached to a rigid ground over its whole length; the latter can be considered to be a continuous sleeper with no gaps. The three models have the same sleeper spacing of $0.6 \mathrm{~m}$ but the widths of the sleepers are $0.1 \mathrm{~m}$ and $0.3 \mathrm{~m}$ in addition to the initial case of $0.2 \mathrm{~m}$. As can be seen, they all demonstrate the acoustic characteristic of a line monopole at low frequency. The narrower sleepers have a lower sound power in the monopole region: it reduces by about $6 \mathrm{~dB}$ when the width is halved from $0.2 \mathrm{~m}$ to $0.1 \mathrm{~m}$. Similarly there is a difference of about $6 \mathrm{~dB}$ between the result for a width of $0.3 \mathrm{~m}$ and the 'continuous sleeper' model. The position of the dip in the spectrum is again affected by the sleeper width but the differences in the region above $500 \mathrm{~Hz}$ are quite small.
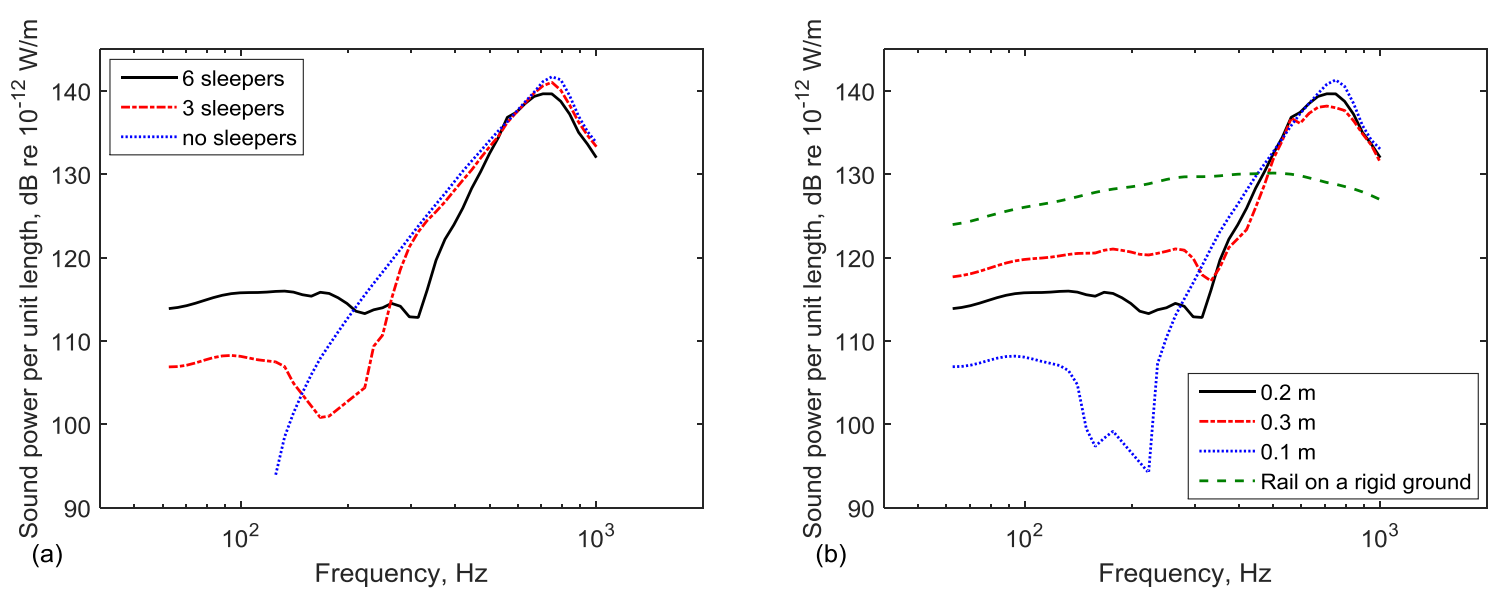

Figure 8 Effects of different sleeper models on the sound power level from the rail from 3D BE model. (a) Different number of the sleepers; (b) Different widths of the sleepers.

\subsection{Results for realistic rail vibration}

Although the radiation from the rail can be reasonably approximated by using a 2D approximation, i.e. a uniform vibration along its length [24], in reality the rail vibration consists of waves with a certain decay rate and phase velocity. To account for this, in this section the velocity of the rail surface in the boundary element model is assigned according to the results of an analytical track vibration model. This represents the rail by a Timoshenko beam on a continuous two-layer support $[2,25]$. 
The results for lateral vibration in Figure 2(b) and Figure 7(b) indicated that there is little difference between the results on a rigid ground and above a rigid/absorptive ground, each of which follows the trend of a line dipole. It is therefore straightforward to devise an average radiation for the lateral direction. Therefore, only the case with vertical vibration is considered here and in subsequent sections as this is the more complex case requiring further analysis.

The corresponding parameters used in the track model are listed in Table 2. Two values of rail pad stiffness are used. In each case, the values of the pad and ballast stiffness are high frequency, dynamic stiffnesses that are applicable to small strain amplitudes. The corresponding predictions of the track decay rate for these two pad stiffnesses are presented in Figure 9(a). The decay rate of the track with stiffer rail pad can be seen higher than that with the softer rail pad above $250 \mathrm{~Hz}$. The ratio of sleeper vibration to rail vibration is shown in Figure 9(b); this will be used in the next section.

The predicted vibration of the rail is used as the input in the BEM model. All points on a given cross-section are assigned the same vertical velocity, i.e. neglecting cross-section deformation; this is reasonable in this frequency region below $1 \mathrm{kHz}$ [24]. Although the length of the model is limited to $3.6 \mathrm{~m}$ on either side of the excitation point, this is sufficient for the current purpose.

The radiation ratio from the rail in each of these cases is compared with the result for uniform vibration of the rail in Figure 10. There is little difference among them. Consequently, the conclusions reached using uniform rail vibration are not affected by the introduction of a more realistic vibration distribution.

At low frequency, below $100 \mathrm{~Hz}$, the results based on uniform vibration (which are equivalent to a $2 \mathrm{D}$ model) have a slope of $10 \mathrm{~dB} /$ decade, which is consistent with a line dipole, whereas those based on using the rail vibration from the track vibration model have a slope that tends to $20 \mathrm{~dB} /$ decade, which is consistent with a point monopole. This occurs due to the strong decay of rail vibration with distance at low frequency. Although this difference is not accounted for when using 2D models, the TWINS model includes a correction term for this effect [24]. 
Table 2 Parameters used for the ballast tracks with soft and stiff rail pads

\begin{tabular}{|l|l|}
\hline Properties & Parameters \\
\hline Rail mass per unit length & $60 \mathrm{~kg} / \mathrm{m}$ \\
\hline Rail vertical bending stiffness & $6.42 \mathrm{MNm}{ }^{2}$ \\
\hline Rail vertical loss factor & 0.02 \\
\hline Sleeper model & Mass \\
\hline Sleeper mass (half sleeper) & $150 \mathrm{~kg}$ \\
\hline Sleeper spacing & $0.6 \mathrm{~m}$ \\
\hline Pad vertical stiffness (soft pad) & $120 \mathrm{MN} / \mathrm{m}$ \\
\hline Pad vertical stiffness (stiff pad) & $400 \mathrm{MN} / \mathrm{m}$ \\
\hline Pad vertical loss factor & 0.2 \\
\hline Ballast vertical stiffness & $100 \mathrm{MN} / \mathrm{m}$ \\
\hline Ballast vertical loss factor & 1.0 \\
\hline
\end{tabular}
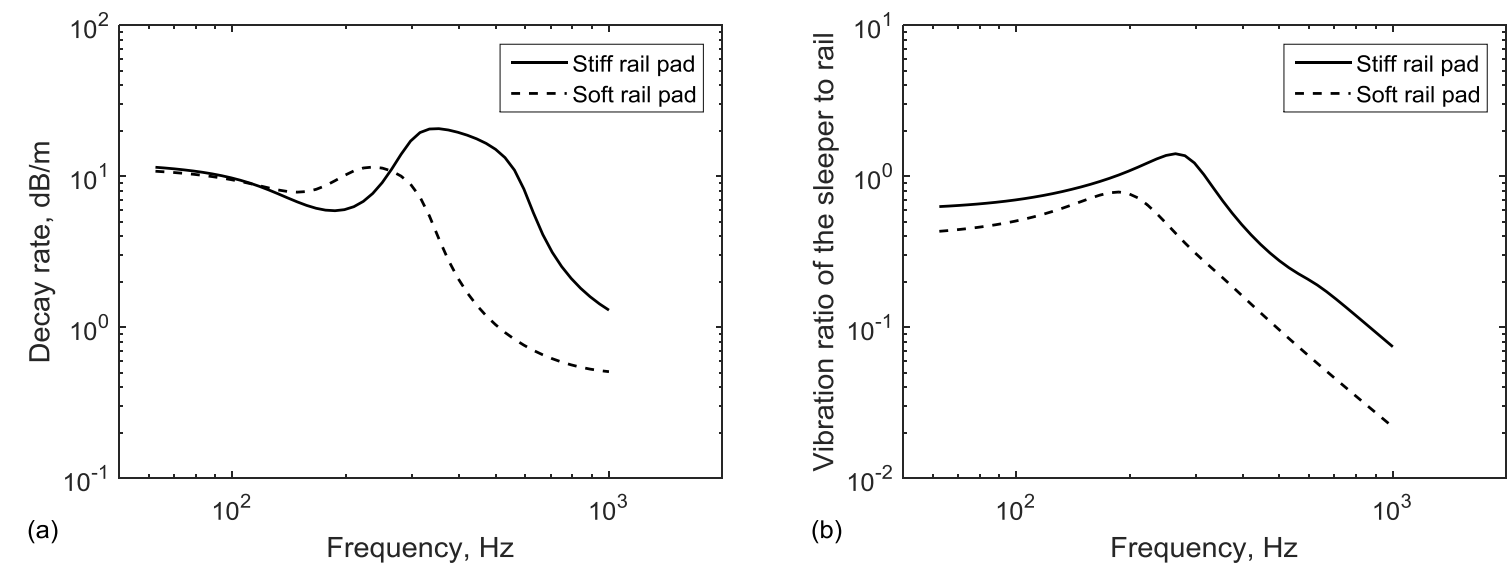

Figure 9 Comparison of the vertical dynamic properties for the two tracks. (a) The track decay rate; (b) The vibration ratio. 


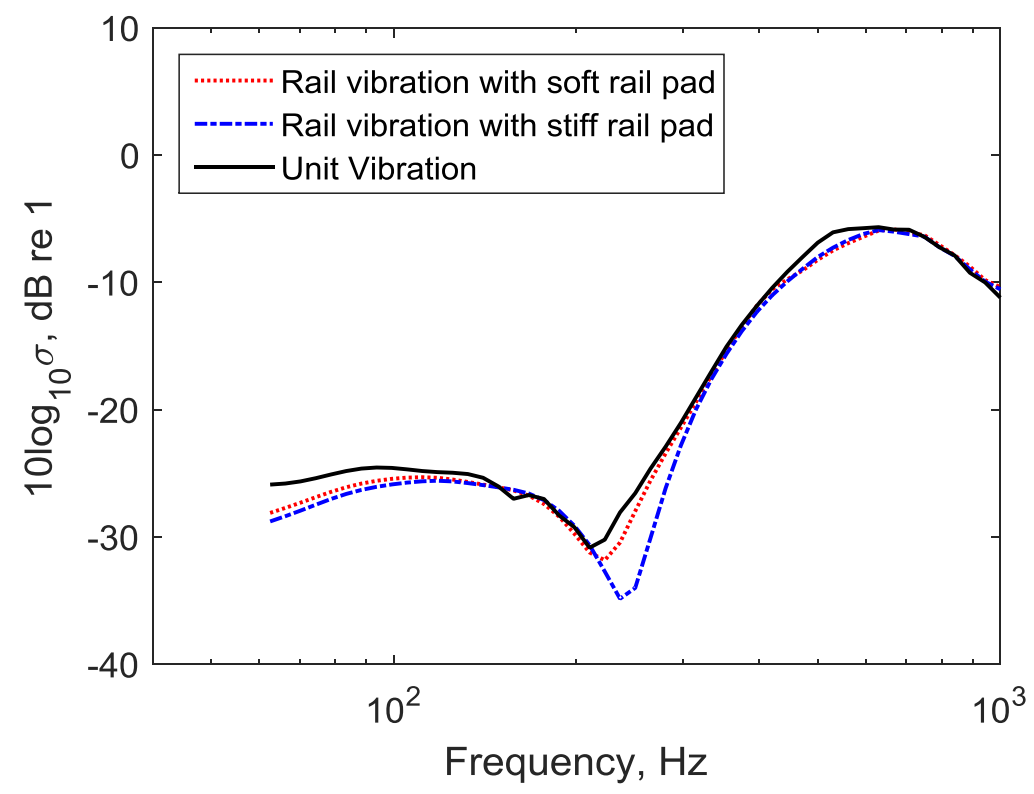

Figure 10 Radiation ratio of the rail in the track for uniform motion of the rail and for rail vibration calculated from Timoshenko beam model

\subsection{Results including sleeper radiation}

In this section the radiation from the sleepers is also included in the above model by assigning the surface of the sleepers a vibration amplitude derived from the same analytical track vibration model; this uses the ratio of the sleeper vibration to the rail vibration shown in Figure 9(b). The rail and sleeper vibration are normalised by the driving point mobility of the rail to give a unit amplitude at the driving point. In order to show the contributions of the different components of the track sound radiation, the results from three calculations are compared, each based on the 3D BEM model shown in Figure 6. In these (i) a single rail and all sleepers are vibrating; (ii) only the rail is vibrating and the sleepers are stationary; (iii) only the sleepers are vibrating and the rail is stationary. Figure 11 shows the sound power per unit length of the track for the two values of rail pad stiffness. Results are shown separately for the radiation from the rail and sleepers as well as the combined radiation. The sleeper vibration leads to a clear increase in the sound power at low frequency. At higher frequency, above $400 \mathrm{~Hz}$ for the soft pad and $600 \mathrm{~Hz}$ for the stiff pad, the results are similar to those obtained for the rail alone. The sleeper is, however, the dominant source of noise from the track below these frequencies. Consequently, the details of the rail radiation at low frequencies observed in Figure 7 are masked by the sleeper contribution. Nevertheless, on a slab track the sleeper contribution is not 
present to this degree, and it will be necessary to account correctly for the rail radiation even at low frequency.
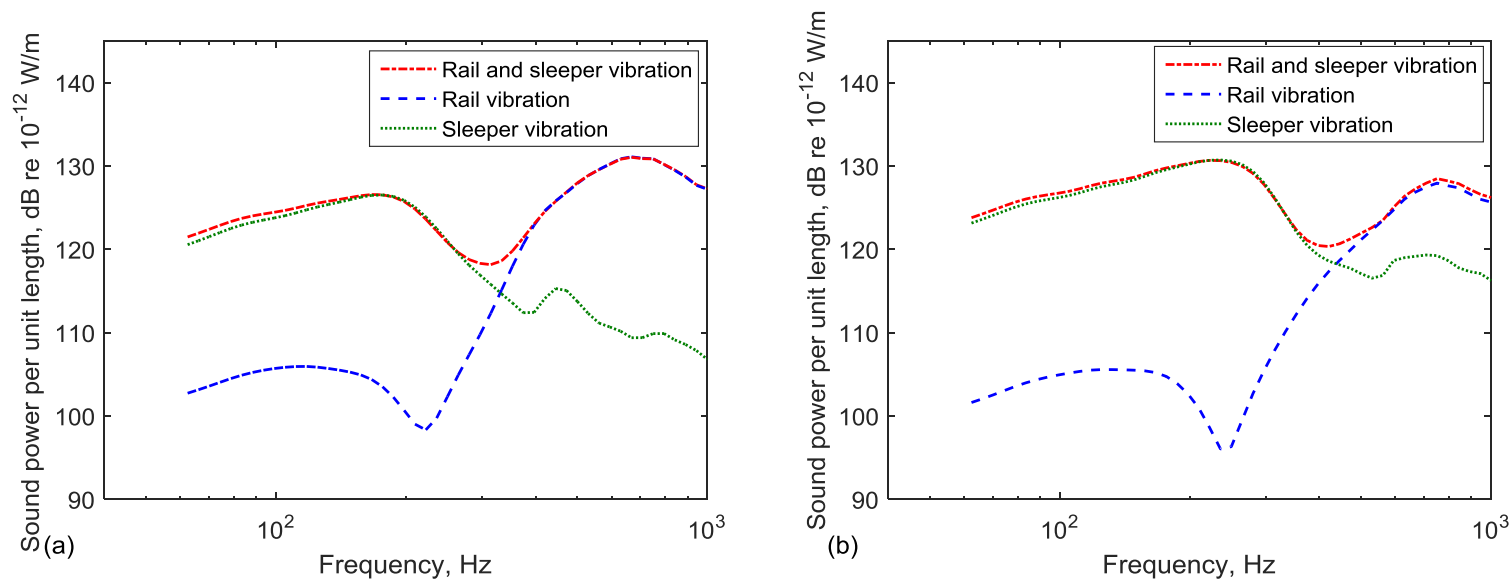

Figure 11 Sound power from the track obtained with and without including sleeper vibration. (a) Soft rail pad; (b) Stiff rail pad.

\section{Proposed model}

\subsection{Discussion in terms of elementary sources}

Before proceeding to present an engineering model for the rail radiation, this section discusses the form of the results obtained using the 3D BEM model for vertical vibration. In particular, it has been observed, in Figure 7(a), that the radiated sound power has a dip at around 200-300 $\mathrm{Hz}$ between the low frequency region where the behaviour follows that of a line monopole and a higher frequency region where it follows that of a line quadrupole.

From Figure 2 it was observed that the oscillating rail in free space behaves as a line dipole below approximately $1 \mathrm{kHz}$. When the rail is attached to a rigid ground it behaves as a line monopole, as the underside of the rail foot is not radiating and consequently the symmetry of the dipole behaviour is disturbed. On the other hand, when the rail is located at a certain distance above the ground the image sources due to the ground reflection combine with the original dipole sources to form a longitudinal quadrupole. These three situations were illustrated in Figure 3.

The results of Figure 7, therefore, represent a combination of monopole sources, corresponding to the parts of the rail directly over the sleepers, and quadrupole sources, corresponding to the sections of rail between the sleepers. The monopole sources are dominant at low frequency and the quadrupole sources at higher frequency. The question arises why there is a dip between 
these two regimes. To understand this it can be observed that the two dipoles making up the quadrupoles consist of outer sources (the top of the rail) which are in phase with the monopoles above the sleepers, and inner sources (the bottom of the rail) which are out of phase with them, see Figure 12. Moreover, at low frequency the various sources are all close together compared with the acoustic wavelength and therefore they strongly interact. The sound power radiated from such an array of elementary sources is generated by the volume velocity of each source in combination with the combined sound pressure on their surfaces due to all sources. So, for example, within a dipole consisting of two contra-phase point sources, the two sources interact so that the pressure due to one source reduces the power radiated by the other. In a longitudinal quadrupole, see Figure 3(c), the two inner sources are closer together than the two outer ones and they therefore reinforce each other more than the outer ones. In the presence of the monopoles above the sleepers, however, see Figure 12, the sound pressure from the monopoles is out of phase with the pressure from these inner sources. At some frequency, where the monopole and quadrupole lines cross, this leads to cancellation between the monopoles and quadrupoles and the radiated power has a minimum. This phenomenon has been confirmed in the BEM calculations of Section 3, in which it has been found that the sound intensity on the surface of the rail foot can become negative in the vicinity of this frequency.

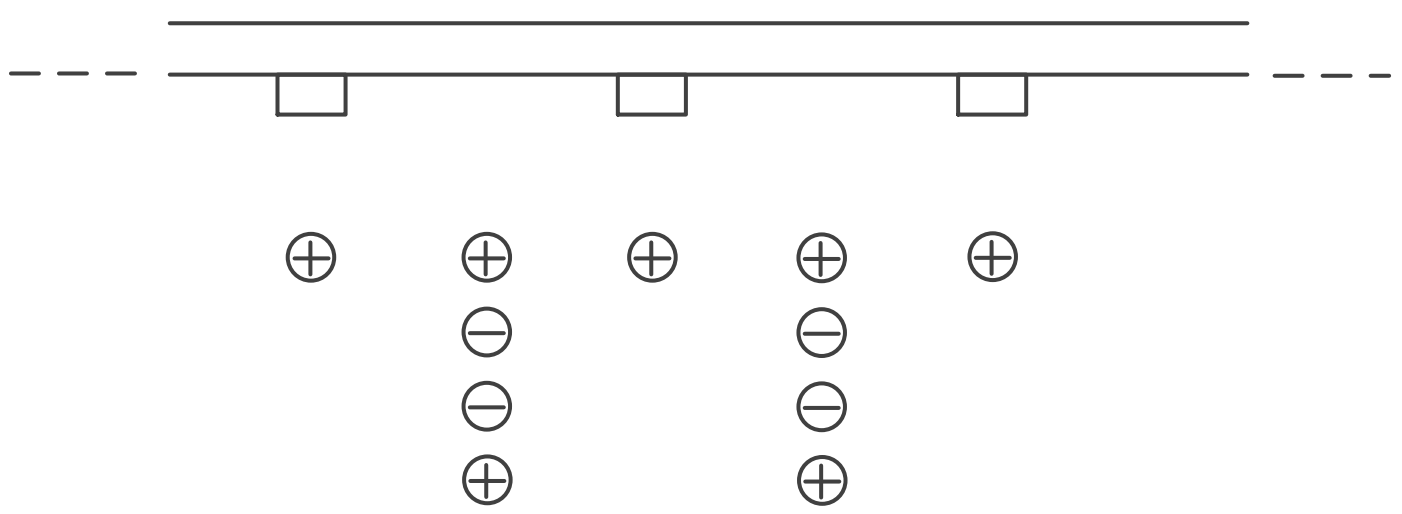

Figure 12 Indication of equivalent elementary sources representing the rail attached to sleepers.

\subsection{Difference between discrete and continuous sources}

From Figure 8 it was observed that either halving the width of the sleepers, or halving the number of sleepers, leads to a $6 \mathrm{~dB}$ reduction in sound power level in the low frequency line monopole region. Moreover, the difference between the result in Figure 8(b) for sleepers that are $0.2 \mathrm{~m}$ wide every $0.6 \mathrm{~m}$ and the result for a continuous sleeper is $20 . \log _{10}(3)=9.5 \mathrm{~dB}$. Thus, the sound power in the monopole region at low frequencies is proportional, not to the area of 
the sleepers, but to the square of this area. A similar effect will apply to the monopole component of the rail radiation.

To demonstrate this effect more explicitly, a simple model is employed here based on the Rayleigh integral [26]. Source regions are chosen that have size $0.2 \times 0.2 \mathrm{~m}$ and are spaced $0.6 \mathrm{~m}$ apart. A total of six such sources are chosen, see Figure 13(a). They represent approximately the monopole regions of the rail above each sleeper. Each source region is assigned a velocity amplitude of $1 \mathrm{~mm} / \mathrm{s}$. The sound power is calculated from a far field integration over a hemisphere and the results are shown in Figure 13(b). They are compared with the corresponding results for a continuous source of width $0.2 \mathrm{~m}$ and the same overall length $(3.6 \mathrm{~m})$. At low frequencies the difference between these two results is $9.5 \mathrm{~dB}$ whereas at high frequencies it is approximately $5 \mathrm{~dB}$. The continuous source has a larger vibrating surface area; this is responsible for the $5 \mathrm{~dB}$ difference at high frequency (due to a factor of 3 in source area). To compensate for this difference the results are expressed in terms of a radiation ratio using Eq. (1). Figure 13(c) shows the radiation ratios of the discrete and continuous sources and Figure 13(d) shows the level difference between them. The difference is now $4.7 \mathrm{~dB}$ at low frequencies and close to 0 at high frequencies. The frequency at which the biggest change occurs is approximately $570 \mathrm{~Hz}$. At this frequency the acoustic wavelength is equal to the spacing between sources, $0.6 \mathrm{~m}$. A second, smaller, shift occurs at twice this frequency.

It has been found that varying the width of the sources or the number of sources included in the model has negligible effect on these results (i.e. Figure 13(d)), whereas varying the spacing between sources shifts the frequency at which the change occurs. These results are consistent with the trends observed in the low frequency results from the 3D track model in Figure 8. 

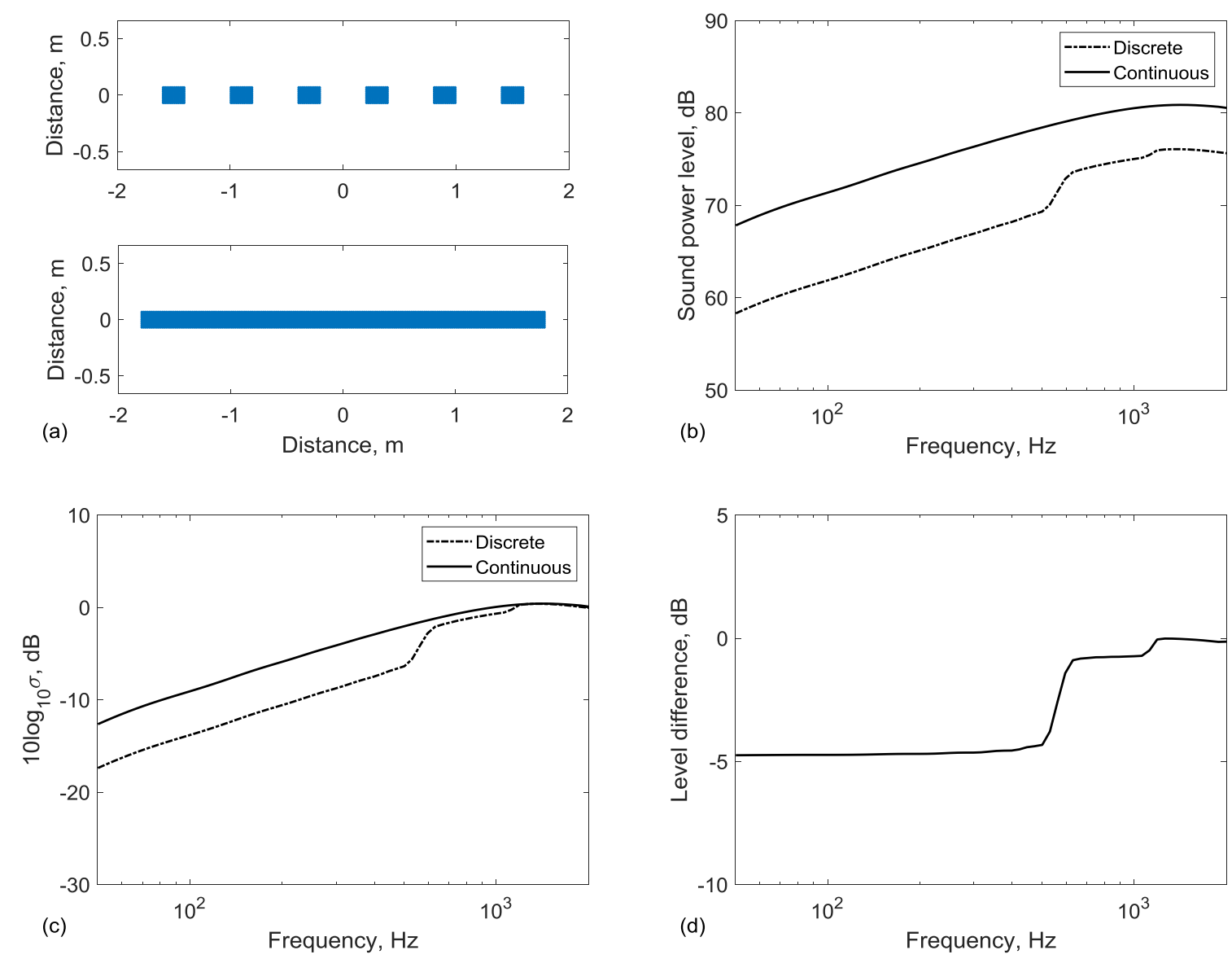

Figure 13 Comparison of sound radiation from discrete and continuous sources. (a) Source positions;

(b) Sound power level; (c) Radiation ratio (in $\mathrm{dB}$ ); (d) Level difference of radiation ratios.

\subsection{Appropriate combination of $2 \mathrm{D}$ results}

The 3D BEM model for the predictions of the rail radiation involves a high computational load, even for the limited length of track considered here. For implementation in an engineering model such as TWINS, therefore, a more practical and approximate approach is required. A proposal is presented in this section and verified by comparison with the results of Section 3.

The approach adopted is based on taking a suitable weighted average of the sound power levels from the two 2D models to take account of the monopole and quadrupole source terms. According to the results in Figure 13, for vertical rail vibration the frequencies above and below a 'cut-off' frequency are considered separately. This frequency is given by $f_{0}=c_{0} / d$ where $c_{0}$ is the acoustic wavespeed and $d$ is the sleeper spacing.

In the region above this cut-off frequency a simple weighted average is used according to the corresponding surface areas:

$$
\sigma=\frac{b}{d} \sigma_{m}+\frac{(d-b)}{d} \sigma_{q} \text { for } f>f_{0}
$$


where $b$ is the width of the sleepers, $d$ is the sleeper spacing, $\sigma_{m}$ is the radiation ratio for the case of a rail on a rigid ground (i.e. monopole) and $\sigma_{q}$ is the radiation ratio for the case of a rail above an absorptive ground (i.e. quadrupole). Both $\sigma_{m}$ and $\sigma_{q}$ are obtained from the corresponding 2D BEM models. Below $f_{0}$ a modified formula is used:

$$
\sigma=\left|\left(\frac{b}{d}\right)^{2} \sigma_{m}-\left(1-\left(\frac{b}{d}\right)^{2}\right) \sigma_{q}\right| \text { for } f<f_{0}
$$

in which the factor $b / d$ is squared and a minus sign is introduced to mimic the cancellation observed between the two components. For the geometry considered in Section 3, the factor $b / d=1 / 3$ and the cut-off frequency $f_{0}=570 \mathrm{~Hz}$. For the lateral rail vibration, the weights of $b / d$ and (1-b/d), according to Eq. (2), are used in the whole frequency range.

Figure 14 compares results from this simplified approach with those from the full 3D BEM model. Results are shown for cases where the ballast surface is either rigid or absorptive. For the vertical vibration of the rail, Figure 14(a), the predictions from the proposed approach agree well with those from 3D model apart from some differences in the frequency range 100-300 Hz. Nevertheless, the trends, including the dips in the results from the 3D model at around 200 $\mathrm{Hz}$ and $300 \mathrm{~Hz}$, are reproduced approximately in the results of the proposed simplified model. However, these differences will be masked by the sleeper noise where this is present. For the lateral motion of the rail, as shown in Figure 14(b), good agreement can be found between the two modelling approaches.
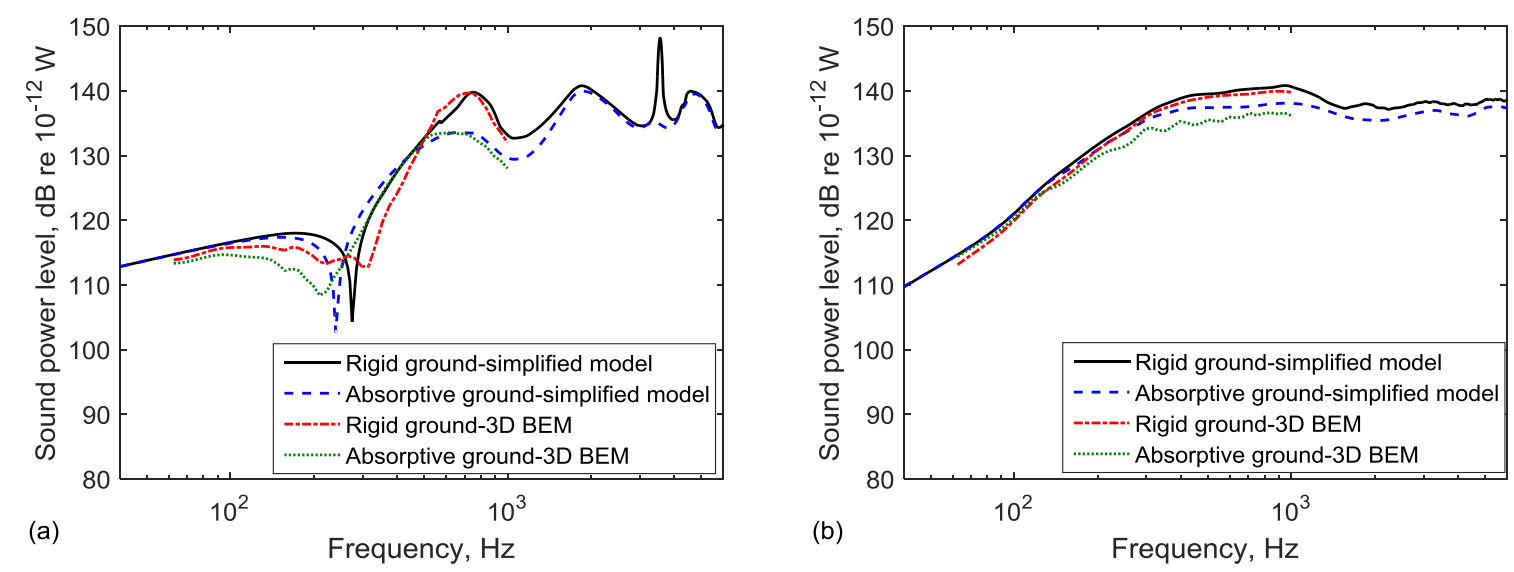

Figure 14 Comparison of the averaged rail radiation between simplified approach and 3D BEM model. (a) Vertical motion; (b) Lateral motion. 


\section{Application to operational tracks}

To illustrate the implications of these new models for the sound radiation from the rails and sleepers of a railway track, in this Section they are applied to operational tracks. The noise from the track is predicted using the TWINS model taking account of the new radiation models for the rail and the sleeper. The influence of the ground on the sound power radiated by the wheel, however, is neglected, because the wheel is far enough above the ground surface, its centre being approximately $0.6 \mathrm{~m}$ above the ground. Nevertheless, the effect of the absorptive ground at the trackside is included in the predictions of sound propagation for all three components. These predictions are compared with existing measurements obtained for two tracks. The first is a ballasted track at Fishbourne, UK [27, 28]. The sound pressure spectrum was measured at a point $7.5 \mathrm{~m}$ away from the track and $1.2 \mathrm{~m}$ above the rail head during the passage of Class 377 Electrostar EMUs at a speed of $118 \mathrm{~km} / \mathrm{h}$. The rail roughness and track decay rates were measured at the site and wheel roughness measurements were available from similar trains [27]. The dynamic properties of the track, including the pad and ballast stiffness and damping, are listed in Table 3. The pad and ballast stiffness values are again high frequency, dynamic stiffnesses. Additionally, results will be shown for a slab track [29], the properties for which are also listed in Table 3.

Table 3 Parameters used for the two tracks

\begin{tabular}{|c|c|c|c|c|}
\hline \multirow[b]{2}{*}{ Rail parameters } & \multicolumn{2}{|l|}{ Ballasted track } & \multicolumn{2}{|l|}{ Slab track } \\
\hline & Vertical & Lateral & Vertical & Lateral \\
\hline Rail cross section & \multicolumn{2}{|l|}{$56 \mathrm{E} 1$} & \multicolumn{2}{|l|}{ 60E1 } \\
\hline Rail bending stiffness & $4.86 \mathrm{MNm}^{2}$ & $0.88 \mathrm{MNm}^{2}$ & $6.42 \mathrm{MNm}^{2}$ & $1.07 \mathrm{MNm}^{2}$ \\
\hline Rail loss factor & 0.02 & 0.02 & 0.02 & 0.02 \\
\hline \multicolumn{5}{|l|}{ Rail pad parameters } \\
\hline Pad stiffness & $120 \mathrm{MN} / \mathrm{m}$ & $15 \mathrm{MN} / \mathrm{m}$ & $1730 \mathrm{MN} / \mathrm{m}$ & $150 \mathrm{MN} / \mathrm{m}$ \\
\hline Pad damping loss factor & 0.25 & 0.25 & 0.2 & 0.15 \\
\hline \multicolumn{5}{|l|}{ Sleeper / baseplate parameters } \\
\hline Sleeper model & Flexible beam & Mass & Mass & Mass \\
\hline Sleeper mass (half) & $150 \mathrm{~kg}$ & $150 \mathrm{~kg}$ & $6.0 \mathrm{~kg}$ & $6.0 \mathrm{~kg}$ \\
\hline Sleeper spacing & \multicolumn{2}{|l|}{$0.65 \mathrm{~m}$} & \multicolumn{2}{|l|}{$0.6 \mathrm{~m}$} \\
\hline \multicolumn{5}{|c|}{ Ballast / baseplate pad parameters } \\
\hline Ballast stiffness per half sleeper & $75 \mathrm{MN} / \mathrm{m}^{*}$ & $75 \mathrm{MN} / \mathrm{m}$ & $75 \mathrm{MN} / \mathrm{m}$ & $35 \mathrm{MN} / \mathrm{m}$ \\
\hline Ballast damping loss factor & $1.0 *$ & 2.0 & 0.2 & 0.15 \\
\hline
\end{tabular}

* Frequency dependent above $100 \mathrm{~Hz}$ [2] 


\subsection{Radiation ratio of the rail and sleeper}

The radiation ratios used for the UIC54 rail are shown in Figure 15 and compared with those used in the existing TWINS model. They are determined based on a model in which the rail is $50 \mathrm{~mm}$ above the absorptive ballast, as in Section 2.1. The same weighting factors (i.e. $b / d=$ 1/3) are used as in Section 4.3.
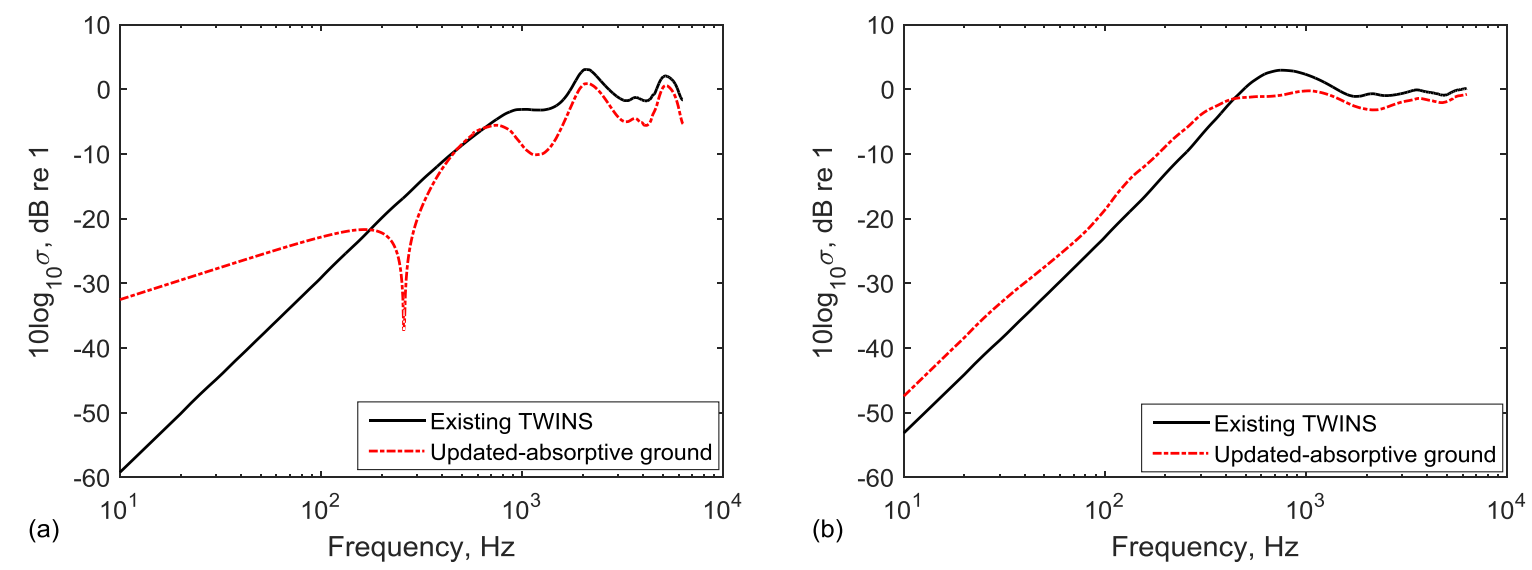

Figure 15 Comparison of the radiation ratios of the rail. (a) Vertical motion; (b) Lateral motion.

For the radiation ratio of the sleepers, the results from Section 2.2 are again considered. They are presented in Figure 16 and compared with the results from the sleeper model currently implemented in TWINS [11]. Note that the prediction of the radiation ratio above $2000 \mathrm{~Hz}$ is extrapolated from the value at $2000 \mathrm{~Hz}$ obtained by using the model in Figure 4. The model from TWINS is an approximation based on the radiation from a rectangular piston set in an infinite baffle, with a heuristic correction intended to allow for the presence of multiple sleepers. It is clear that this correction leads to an over-estimate of the noise at low frequency compared with the current results. 


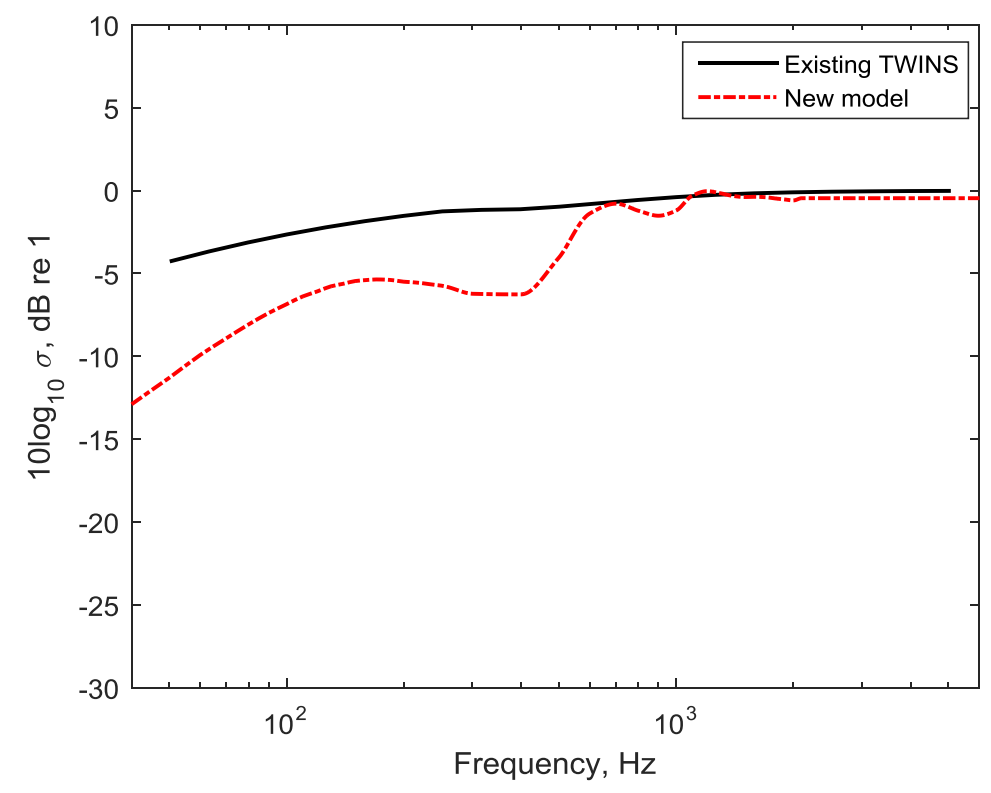

Figure 16 Comparison of the radiation ratio of the sleeper

\subsection{Prediction of the sound radiation from different components in the track}

The predicted A-weighted sound pressure of the different components in the ballasted track at the microphone position are shown in Figure 17. Results are shown for the existing TWINS model and using the new radiation models. As can be seen, these predictions demonstrate the typical features for the sound radiation from a ballasted track. Specifically, the sleeper dominates the track sound radiation at the low frequency, whereas the rail radiation becomes important in the mid-frequency range. The wheel, however, is the dominant noise source at high frequency. For the sound pressure component from the rail, there are differences of $4 \sim$ $10 \mathrm{~dB}$ between the results of these models below $200 \mathrm{~Hz}$. However, in this frequency region the sleeper is actually the dominant source. Hence, although the contribution from the rails is modified by the new models at low frequency, this difference will not affect the total noise for a ballasted track such as this. As expected from the radiation ratios shown in Figure 16, the contribution from the sleepers obtained by using the current models is lower than that obtained based on the existing TWINS model especially below $630 \mathrm{~Hz}$. The sound pressure component from the wheels is the same in both models. As can be seen by comparison with the other components, the wheel has the highest contributions to the total noise at high frequencies, above about $2 \mathrm{kHz}$. 


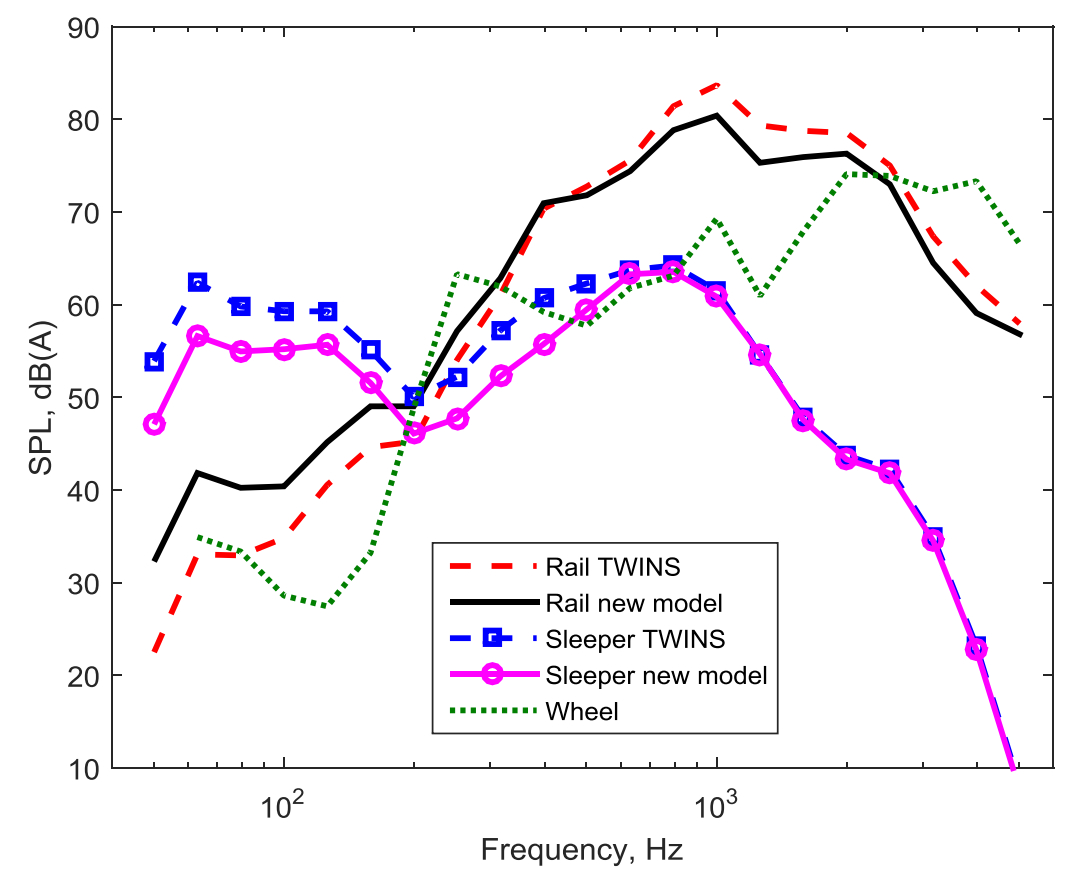

Figure 17 Comparison of the predicted A-weighted sound pressure level of the different components in the track

\subsection{Comparison with measurements}

The measured and predicted total A-weighted sound pressure levels are shown in one-third octave bands in Figure 18(a) for this ballasted track. Good agreement can be seen between the measurements and both predicted spectra, bearing in mind that the measured results are subject to a variation of $+/-3 \mathrm{~dB}$ in each $1 / 3$ octave band due to variations in train speed, wheel roughness and temperature [28]. The new radiation ratios have a significant effect below 200 $\mathrm{Hz}$, and in the current example show improved agreement with the measurements. The differences between the models are smaller at higher frequencies, with a small reduction seen in the rail component between 800 and $1600 \mathrm{~Hz}$. The wheel component dominates the noise above $2 \mathrm{kHz}$, which remains invariant in the different predictions.

Results are shown in Figure 18(b) for a slab track from [29]. Here the slab and wheel predictions are the same in both cases but the rail radiation is updated by the new model. In this case the increase in the rail radiation at low frequencies introduced by the new models is evident in the total noise prediction, as the slab only contributes significantly below $100 \mathrm{~Hz}$ [29]. This yields an improved agreement with the measurements between 100 and $800 \mathrm{~Hz}$. 

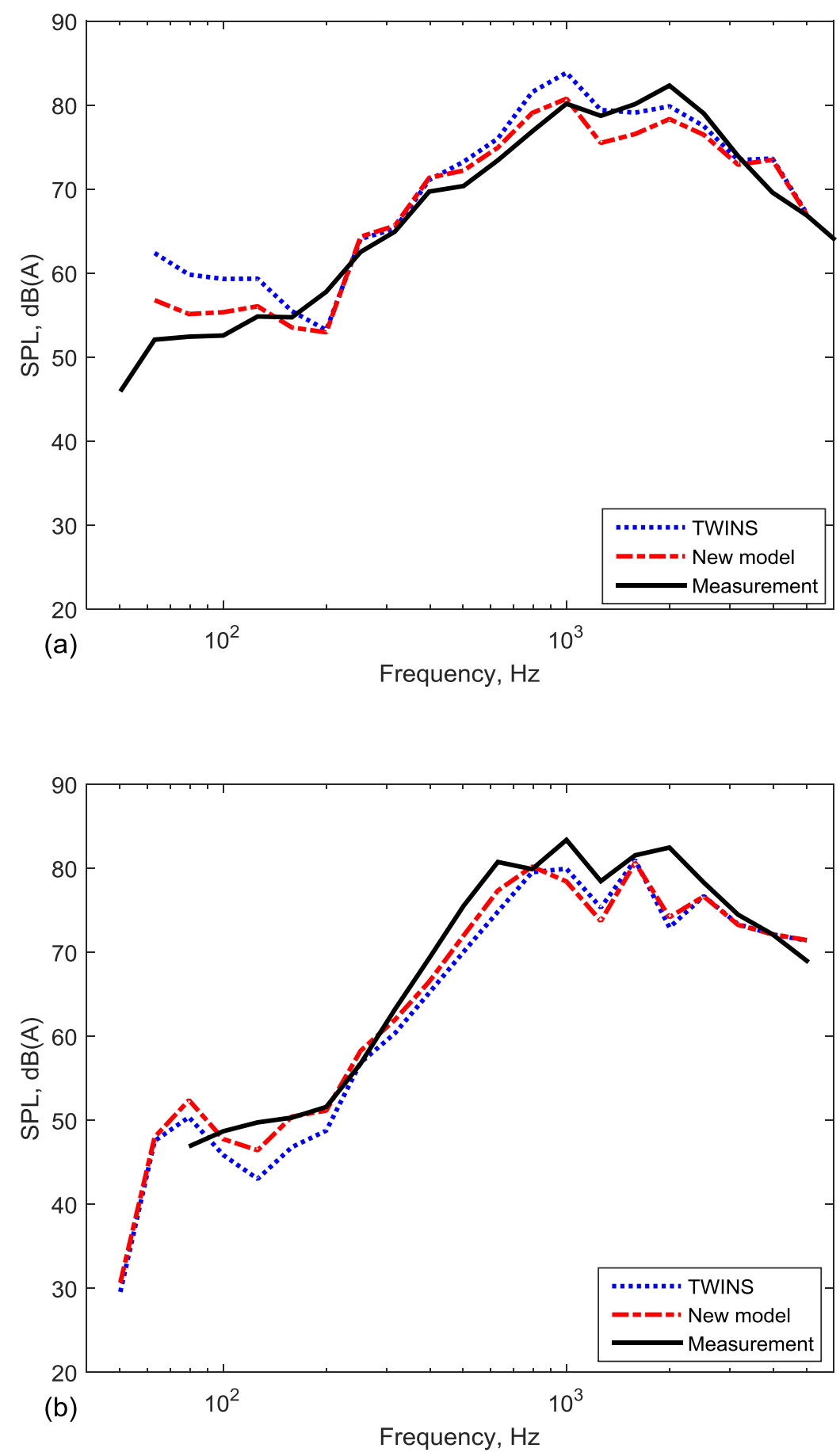

Figure 18 Comparison of A-weighted sound pressure spectra between different predictions and the measurements. (a) Ballasted track; (b) slab track

\section{Conclusions}

A new engineering model has been proposed to predict the sound radiation from the rails and sleepers of a ballasted track, which is more realistic and rigorous than the original TWINS model. In particular, the updated model for the rail radiation is based on a weighted average of 
the results obtained by using $2 \mathrm{D}$ boundary element models, allowing for the fact that the rail is either attached to a rigid ground (concrete sleeper) or located above an absorptive ground (ballast bed). These two situations exist alternately in the track system. For frequencies at which the sleeper spacing is larger than the acoustic wavelength a simple weighted average is taken. However, at low frequencies, for the vertical component of noise, modified weighting factors are introduced to allow for interaction between the different sources. This new model is verified by using a 3D boundary element model of the track. For the improved sleeper radiation model, results from a 3D BEM model are used including three sleepers and an absorptive ballast surface. The main advantage of the new models is that the differences between ballasted tracks and slab tracks can be more accurately determined, whereas in the previous models in TWINS no explicit account was taken of the differences introduced to the sound power by the ground impedance.

The new models for the rail and sleeper radiation have been combined with the TWINS model to predict the sound radiation from operational tracks and comparisons have been made with field measurements. Differences are introduced in the sound radiation components predicted for the rails and the sleepers, particularly at low frequency. Generally good agreement is seen with field measurements. The new models are found to give an improvement at low frequencies, where the sleeper is the dominant noise source. For the case of a slab track improved agreement is obtained below $800 \mathrm{~Hz}$.

Although the models have been used here with the Delany and Bazley impedance model for the ballast, the approach can also be used with other more advanced impedance models. It is recognised that the approximation introduced by this ballast model may contribute to the remaining differences between predictions and measurement data. More advanced models of ballast absorption would be required to investigate the potential for reducing rail noise by changing the ballast composition.

\section{Acknowledgements}

The work described here has been supported by the EPSRC under the programme grants EP/H044949/1, 'Railway Track for the $21^{\text {st }}$ Century (Track 21)' and EP/M025276/1, 'The science and analytical tools to design long life, low noise railway track systems (Track to the Future)'. 


\section{References}

[1] D.J. Thompson. Predictions of acoustic radiation from vibrating wheels and rails. Journal of Sound and Vibration, 120, 275-280, 1988.

[2] David Thompson. Railway noise and vibration mechanisms, modelling and means of control. Elsevier, 2008.

[3] P.J. Remington. Wheel/rail noise-part iv: rolling noise. Journal of Sound and Vibration, 46, 419-436, 1976.

[4] P. J. Remington. Wheel/rail noise-part 1 characterization of the wheel/rail dynamic system, Journal of Sound and Vibration, 46, 359-380, 1976.

[5] P. J. Remington. Wheel/rail rolling noise I: theoretical analysis. Journal of the Acoustical Society of America, 81, 1805-1823, 1987.

[6] C. I. Chessell. Propagation of noise along a finite impedance boundary. Journal of the Acoustical Society of America, 62, 825-834, 1977.

[7] D.J. Thompson, B. Hemsworth, N. Vincent. Experimental validation of the TWINS prediction program for rolling noise, Part 1: description of the model and method. Journal of Sound and Vibration, 193, 123-135, 1996.

[8] D.J. Thompson, P. Fodiman, H. Mahé. Experimental validation of the TWINS prediction program for rolling noise, part 2: results. Journal of Sound and Vibration, 193, 137-147, 1996.

[9] X. Zhang, G. Squicciarini, D.J. Thompson. Sound radiation of a railway rail in close proximity to the ground, Journal of Sound and Vibration. 362, 111-124 (2016).

[10] J. Ryue, S. Jang, D.J. Thompson. A wavenumber domain numerical analysis of rail noise including the surface impedance of the ground, Journal of Sound and Vibration. 432, 173-191 (2018).

[11] D.J. Thompson, M.H.A. Janssens, F.G. de Beer. TWINS: Track-Wheel Interaction Noise Software, theoretical manual (version 3.0). TNO report HAG-RPT-990211, Delft, 1999.

[12] X. Zhang, D.J. Thompson, G. Squicciarini. Sound radiation of railway sleepers, Journal of Sound and Vibration. 369, 178-194 (2016).

[13] K. Attenborough, P. Boulanger, Q. Qin, R. Jones. Predicted influence of ballast and porous concrete on rail noise, Internoise 2005. Brazil.

[14] R.A. Broadbent, D.J. Thompson, C.J.C. Jones. The acoustic properties of railway ballast. Euronoise 2009, Edinburgh. 
[15] X. Zhang, D.J. Thompson, H. Jeong, G. Squicciarini. The effects of ballast on the sound radiation from railway track, Journal of Sound and Vibration. 399, 137-150 (2017).

[16] M.E. Delany, E.N. Bazley. Acoustical properties of fibrous absorbent materials, Applied Acoustics. 3, 105-116 (1970).

[17] K. Heutschi. Sound propagation over ballast surfaces, Acta Acustica united with Acustica. 95, 1006-1012 (2009).

[18] D. Dragna, P. Blanc-Benon, Physically admissible impedance models for time-domain computations of outdoor sound propagation, Acta Acustica united with Acustica 100, 401-410 (2014)

[19] M. Bérengier, M. R. Stinson, G. A. Daigle, J. F. Hamet. Porous road pavement: acoustical characterization and propagation effects. Journal of the Acoustical Society of America 101 (1997) 155-162.

[20] K. Attenborough: Acoustical characteristics of rigid fibrous absorbents and granular materials. Journal of the Acoustical Society of America 73, 785-799 (1983).

[21] K. Attenborough, I. Bashir, S. Taherzadeh. Outdoor ground impedance models. Journal of the Acoustical Society of America 129, 2806 - 2819 (2011)

[22] J.F. Allard, N. Atalla. Propagation of Sound in Porous Media: modelling sound absorbing materials. Wiley, Chichester, 2009.

[23] D.L. Johnson, J. Koplik, R. Dashen. Theory of dynamic permeability and tortuosity in fluid-saturated porous media. Journal of Fluid Mechanics, 176, 379-402, 1987.

[24] D.J. Thompson, C.J.C. Jones, N. Turner. Investigation into the validity of twodimensional models for sound radiation from waves in rails. Journal of Acoustical Society of America, 113, 1965-1974, 2003.

[25] S. L. Grassie, R. W. Gregory, D. Harrison and K. L. Johnson. The dynamic response of railway track to high frequency vertical excitation. Journal of Mechanical Engineering Science, 24, 77-90, 1982.

[26] J.W. Strutt (Lord Rayleigh). Theory of Sound, $2^{\text {nd }}$ edition. Dover Publications, New York, 1945.

[27] G. Squicciarini, M.G.R. Toward, D.J. Thompson. Experimental procedures for testing the performance of rail dampers, Journal of Sound and Vibration. 359, 21-39 (2015).

[28] G. Squicciarini, D.J. Thompson, M.G.R. Toward, R.A. Cottrell. The effect of temperature on railway rolling noise, Journal of Rail and Rapid Transit 230, 1777-1789, 2016. 
[29] X. Zhang, H. Jeong, D.J. Thompson, G. Squicciarini. The noise radiated by ballasted and slab tracks. Applied Acoustics 151, 193-205, 2019. 